
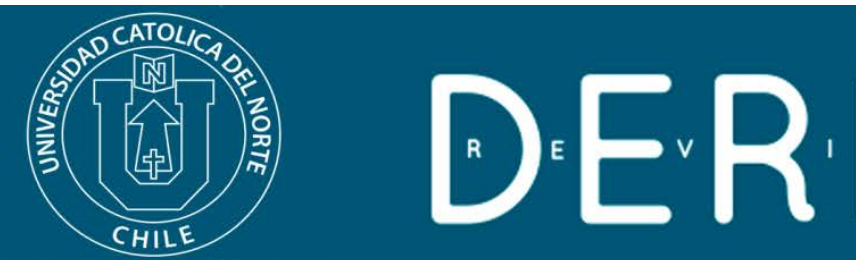

do) $10.22199 /$ issn.0718-9753-2021-00011

REVISTAS CIENTÍFICAS

revisistas.uchecal
rel

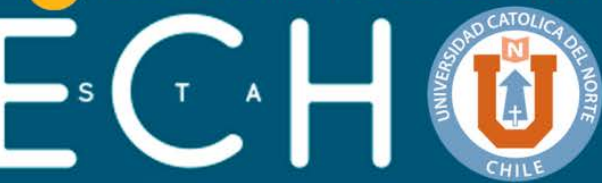

C o qu i m bo

ISSN: 0718-9753 (En línea)

\title{
Fundamentos jurídicos y de análisis económico para la apli- cación de responsabilidad civil por incumplimiento de de- beres matrimoniales en el derecho chileno
}

\section{Legal grounds and economic analysis for the application of civil lia- bility for breach of matrimonial duties under Chilean law}

Felipe Javier Castro Azócar ${ }^{1}$ (D) https://orcid.org/0000-0002-8674-876X

'Universitat de Girona, Doctorando en Derecho, Economía y Empresa, Girona, España. Máster en Análisis Económico del Derecho, U. Complutense de Madrid, España.

๑fcastroaz@gmail.com

(cc) BY

Resumen:

Se busca defender la procedencia de la indemnización de perjuicios ante el incumplimiento de deberes matrimoniales, bajo el estatuto de la figura del daño moral y con causa del divorcio sanción que se establece en la Ley $N^{\circ}$ 19.947. Para ello, se recogen argumentos de legislación nacional, comparada, como asimismo de doctrina y jurisprudencia, incorporando también fundamentos de análisis económico del derecho.

Palabras Clave: Deber de fidelidad; Daño moral; Análisis económico del derecho.

\begin{abstract}
:
It seeks to defend the appropriateness of compensation for damages for breach of marital duties, under the statute of the figure of moral damages and cause of guilt divorce established in Law No. 19.947. In order to do so, arguments are gathered from national and comparative legislation, as well as from doctrine and jurisprudence, also incorporating foundations of economic analysis of the law.

Keywords: Duty of fidelity; Moral damage; Economic analysis of law.
\end{abstract}


Fundamentos jurídicos y de análisis económico para la aplicación de responsabilidad civil...

\section{Introducción}

Este texto nace con la motivación de ahondar en temáticas que en nuestra sociedad, con el pasar de los años, se hace cada vez más necesario afrontar y, en muchas ocasiones, reformular. Ello ya sea se haga referencia a los argumentos y presupuestos dogmáticos que las sostienen, como también, a la esencia misma de las instituciones que rigen a las personas.

Lo particular de estas materias de derecho familiar está dado en la necesaria revisión que exigen sus reglamentaciones y, en específico, las que atañen a las normas que definen directrices de comportamiento que contienen un indiscutible y fuerte contenido valórico, inspirando aquél en una determinada cosmovisión que las informa.

Es por esto que, principalmente, y asumiendo la utilidad que tiene un análisis de este tipo, es que en el trabajo que se presenta se hará el intento de abordar la situación de los deberes matrimoniales, con especial énfasis en el deber de fidelidad, consagrados en el Código Civil chileno (2000, art. 131) ${ }^{1}$, y su aplicación en los sistemas resarcitorios que entrega el derecho civil (de responsabilidad o derecho de daños $y$, en específico, respecto al daño moral) para, a continuación, esbozar la pertinencia o no de ésta conexión (si es que existe) de figuras para los tiempos que corren, en que, especialmente la fidelidad y los vínculos afectivos, pareciesen haber perdido terreno, dando lugar a una idiosincrasia sostenida en relaciones menos rígidas, más flexibles o liberalizadas. Rodríguez Pinto (2017) se refiere a este fenómeno como "la desvalorización del matrimonio", como parte de las tendencias actuales del derecho de familia.

Asumiendo desde ya que el matrimonio es una institución que surge a partir del contrato mismo que lo lleva a cabo, no puede llevarse la discusión de sus efectos del mismo modo del que se realiza a propósito de cualquier contrato o acto jurídico, toda vez que no cabe duda que la relación entre cónyuges no puede ser la misma que tienen el comprador y el vendedor en una compraventa o quienes exigen una letra de cambio, dado que el objeto de la relación jurídica no es el mismo (Güitrón Fuentevilla, 2016, p. 10), a pesar su génesis voluntaria. Pero en una sociedad en donde el vínculo matrimonial se ha debilitado considerablemente con el paso del tiempo -afirmación que se respalda con los datos arrojados en los últimos años sobre la notable disminución de matrimonios $(T 13,2019)$ y aumento exponencial de divorcios, además de la numerosa cantidad de hijos nacidos fuera del matrimonio (González Isla, 2006)- y en que se da a entender que las uniones conyugales responden a perspectivas anacrónicas cuya aplicación se da en primacía en sectores conservadores de

\footnotetext{
${ }^{1}$ Sin perjuicio de aquellos que se encuentren en otros artículos del Código Civil o se desprendan de definiciones y principios mismos que informan el derecho de familia.
} 
la población (según algunos), poner en entredicho este asunto (como ya se afirmó en algún párrafo anterior) es una tarea que se dicta para así el día de mañana estar en armonía con nuestras instituciones.

Expuesto lo anterior, este trabajo en primer lugar abordará la discusión sobre la naturaleza jurídica de los deberes matrimoniales para, en segundo término, plantear un análisis respecto a la aplicación (o no) de los aparatos resarcitorios que entrega el derecho común ante el incumplimiento de deberes matrimoniales (específicamente el de fidelidad, que es el principal objeto de este estudio) agrupando al respecto legislación, doctrina y jurisprudencia tanto a nivel local como comparado. De forma sucesiva, me referiré a la compensación económica y a la defensa de su naturaleza eminentemente económica, con la finalidad de despejar eventuales confusiones que puedan suscitarse entre dicha figura y la de la indemnización de perjuicios y, ya resuelto ello, se responderá a la pregunta que recae sobre si es posible homologar o no lo discutido al Acuerdo de Unión Civil. Finalmente, como cuestión aparte se hará una breve referencia a la conexión existente entre el análisis económico del derecho y el derecho de daños en materia de familia, para dar fe del cómo desde dicha disciplina es posible argumentar a favor de la procedencia de la indemnización ante el incumplimiento de los deberes matrimoniales.

\section{De la naturaleza de los deberes matrimoniales}

Interesante discusión se ha dado respecto a los deberes conyugales, de modo tal que se han planteado distintas visiones que recaen sobre la naturaleza de estos. Ya sea desde quienes no los consideran como obligaciones ni tampoco reconocen su juridicidad en virtud de su mero carácter ético, como un sector que hace hincapié en las efectivas consecuencias jurídicas que produce su incumplimiento, la importancia de esta disputa no ve sus fronteras en el simple campo teórico, sino que tiene un fuerte impacto en la práctica.

Ante lo dicho, se puede sugerir de lleno que la dicotomía entre deber-ético y deber-jurídico debe ser superada en virtud del reduccionismo que ella en sí representa. En efecto, pensar el ordenamiento jurídico como un ente aislado y ajeno a la ética es un planteamiento equívoco que se ha agudizado cada vez más en las sociedades contemporáneas y sobre todo en lo que respecta al derecho civil y privado en general. Se ha de convenir que, al tener el derecho un propósito, cualesquiera sean las ramas que lo integren, ese mismo ethos es el que en sí le otorga directrices éticas. De este modo, lo correcto sería sentar posturas a partir de las definiciones de un carácter ético-moral o uno ético-jurídico en razón al tipo de responsabilidad que contraiga la infracción de cada uno de dichos deberes, ya sea moral por un lado (juicio de reproche interno) o jurídica por el otro (consecuencias externas, propias de las obligaciones). 
Fundamentos jurídicos y de análisis económico para la aplicación de responsabilidad civil...

\subsection{El carácter ético-moral}

Ramos Pazos (2010, p. 16) señala que el contenido del derecho familiar, y como consecuencia de ello, el de los efectos personales del matrimonio, es eminentemente ético, reservándole la observancia de los mismos a la intimidad de la pareja y a la sola conciencia de los individuos, descartando por ende su cumplimiento judicial y por consiguiente su entidad como obligación privándolos de los efectos propios de ella.

Esto en un principio resulta de toda obviedad ya que, por ejemplo, ningún tribunal podría obligar a otro a mantener una relación de lecho y techo con su cónyuge, razón por la cual dicha actitud solo traería un juicio de carácter psicológico por parte de quien ejecuta o se abstiene de llevar a cabo ciertas acciones, símil afirmación emplea Ramos Pazos (2010) al sostener que:

... fácil es entender que si una mujer casada, por ejemplo, quiere dejar el hogar común, no se le va a poder obligar a que permanezca en él. Por su naturaleza no es posible obtener un cumplimiento forzado de esa obligación, quedando su cumplimiento entregado al sentido ético del cónyuge. (pp. 16-17)

La responsabilidad moral surge así, sostiene Corral Talciani (2013), "de la violación consciente o culposamente ignorada de las exigencias que la ley moral establece para un buen ejercicio de la libertad en una situación concreta" (p. 10). Dicho esto: ¿Será posible sostener que los deberes que nacen del matrimonio solamente obedecen a la ley moral? O, expresado de otra manera: ¿Hay silencio en la ley respecto a los efectos de la omisión de ellos? Pues, efectivamente los deberes matrimoniales, en su mayoría, sí encuentran un espaldarazo de nuestra legislación. Distinto es, como lo esboza del Picó Rubio (2016), que por ser una emanación del matrimonio no puedan ser analizados con criterios similares a los aplicables a los derechos y obligaciones del derecho civil patrimonial, "lo que no significa que su infracción no esté sancionada por el derecho" (p. 159). El mismo autor enfatiza que:

Los efectos personales del matrimonio poseen una naturaleza claramente civil, por cierto, tomando en cuenta los principios y características del derecho de familia, de ahí que se entienda según el deber que se hable, no proceda el cumplimiento forzado, como es evidente respecto del deber de fidelidad. (del Picó Rubio, 2016, p. 159)

No es posible compartir, sin embargo, el tono empleado (el cual se rescata del contexto en que se utilizan las palabras) por el académico esta vez al referirse al deber de fidelidad ya que, a pesar de que hay acuerdo en que es un deber del cual no puede pedirse su cumplimiento forzadamente, no está, por ser tal, exento de consecuencias jurídicas. De haberse pensado de esa manera por el legislador, éste hubiese 
procurado usar un lenguaje de tal forma que se así se entienda, como por ejemplo hace el Código Civil y Comercial argentino (Ley N²6.994, 2015, art. 431) que se refiere al deber de fidelidad de forma expresa como un deber moral -esta es una novedosa incorporación pues, anteriormente, el Código de Vélez Sarsfield (1869) en la consagración que hacía de éste y otros deberes que derivan del matrimonio en su art. 198, omitía hacer referencia alguna en relación con el eventual carácter que se le podría asignar a aquellos, tal como lo hace hasta hoy el art. 131 del Código Civil chileno (2000)-. El derecho chileno cuando no ha querido reconocer consecuencia jurídica alguna lo ha hecho expresamente. Tal caso ocurre, por ejemplo, con la situación de los esponsales y la expresa mención que hace el legislador en el Código Civil (2000) al referirse "...que las leyes someten enteramente al honor y conciencia del individuo, y que no produce obligación alguna ante la ley civil" (art. 98). Inclusive, existe discusión por parte de los estudiosos respecto a que ni siquiera podrían constituir una obligación natural (afirmando esto algunos debido a la imposibilidad de proceder caución, que es uno de los efectos propios de las obligaciones naturales), razón por la cual devengaría en un simple deber moral en estricto rigor.

Aun así, lo interesante es la aceptación que hace de una naturaleza sui generis de estos deberes, los cuales, si bien el autor no los considera obligaciones, no descarta, sin embargo, dada su naturaleza civil, que puedan producir ciertos efectos jurídicos determinados. A propósito del deber de fidelidad, Quintana Villar $(2015$, p. 128) si bien al igual que los autores mencionados asume el carácter eminentemente moral de aquél, pese a ello sí reconoce que su infracción trae aparejada diversas consecuencias jurídicas, otorgándole el derecho para ello acciones al cónyuge inocente.

\subsection{El carácter ético-jurídico}

Se afirmó en el punto anterior que los deberes matrimoniales sí encontraban espacio dentro del ordenamiento jurídico. En este sentido, el Código Civil (2000) expresamente reconoce algunos de ellos al señalar que "Los cónyuges están obligados a guardarse fe, a socorrerse y ayudarse mutuamente en todas las circunstancias de la vida" (art. 131). Es más, no solo se encuentra con un simple reconocimiento que hace el Código Civil (2000) de aquellos, pues, en la Ley $\mathrm{N}^{\circ} 19.947^{2}$ (2004), resulta posible fijar constancia de como la normativa expresamente reconoce resultas de ellos al rezar que "El divorcio podrá ser demandado por uno de los cónyuges, por falta imputable al otro, siempre que constituya una violación grave de los deberes y obligaciones que les impone el matrimonio" (art. 54). ¿No da acaso esta norma fe del carácter jurídico de estos deberes? Es decir, ¿se podría sostener que aquellos traen consigo solamente un reproche moral propio del sujeto que actúa y no posibles consecuencias jurídicas ante su infracción? Pareciese que no, toda vez que si fuese de ese modo el legislador no se habría molestado en plasmarlos a lo largo de todo el cuerpo nor-

\footnotetext{
${ }^{2}$ Que establece la Nueva Ley de Matrimonio Civil.
} 
Fundamentos jurídicos y de análisis económico para la aplicación de responsabilidad civil...

mativo (Código Civil, 2000, arts. 131, 133, 136 y 321, no. 1, por mencionar diversas disposiciones) -apegándose a esta idea, Ruz Lártiga (2014, pp. 210-211) plantea que los efectos del matrimonio no son normas morales, ya que, al estar consagradas en el Código Civil (2000), son constitutivas de normas jurídicas- dándole además la posibilidad al cónyuge inocente de demandar divorcio por culpa, separación judicial o separación judicial de bienes cumpliéndose los presupuestos exigidos por la ley para cada una de estas acciones. Incluso, respecto al deber de fidelidad, se fue más allá a tal punto de establecer en el Código Civil (2000, art. 132) al adulterio como infracción grave a aquél, cuestión que refleja aún más la convicción del legislador por no dejar su violación (ni la de los otros deberes) al único arbitrio de lo que dicta el fuero interno del comitente en el caso concreto de aplicación.

Si bien aún podrían quedar dudas respecto al carácter de estos deberes al no ser, efectivamente, susceptibles de cumplirse forzadamente, el hecho de que no constituyan obligaciones propiamente tal (desde un punto de vista teórico) no es manifestación de que no puedan ser denominados como de naturaleza jurídica. Así lo plantea Abeliuk Manasevich (2014, p. 36), quien descarta hacer sinónimos obligación y deber jurídico, elaborando una relación género-especie entre ambos conceptos donde el primero es la especie y el segundo es el género. A pesar de que podría (y de ese modo se ciñe el mismo autor al respecto) señalarse que aun así los deberes maritales no serían jurídicos al no ser impuestos coactivamente, hay que tomar en consideración que, según el mismo, más que aquello, lo importante y lo que le otorga la calidad de tales es la sanción que le da el legislador a su inobservancia (Abeliuk Manasevich, 2014, p. 36), cuestión que sí ocurre con la casi gran mayoría de los deberes que emanan del vínculo conyugal.

Relacionado con lo anteriormente expuesto, una postura interesante es la que entrega Barrientos Grandón (2011, p. 474), quien señala que Andrés Bello destaca la juridicidad de los deberes que nacen del matrimonio al tratarlos a propósito el título VI del libro I del Código bajo la expresión "Obligaciones y derechos entre cónyuges", lo que se diferencia del Code Civil', el cual empleaba la voz "deberes". Así las cosas, el razonamiento que entrega el autor sin lugar a duda es valioso en cuanto se afirma y reafirma, con argumento de texto, el efecto jurídico de los mismos.

Hay que agregar también, respecto a esta arista, otras posiciones en torno al punto referido que resultan llamativas, como la de Tapia Rodríguez (2016), quien toma una postura sobre la cual descansa la idea de que los deberes conyugales "... desde el mismo momento en que se encuentran descritos en la ley, son deberes de naturaleza jurídica, pero por su propio contenido ético, el derecho no puede obligar a los cónyuges a cumplirlos de manera forzada o a indemnizar su incumplimiento" (p. 169). Es decir, este último autor reconoce la naturaleza jurídica de los mismos pero resalta que dado su predominante carácter ético no constituirían obligaciones pro-

\footnotetext{
${ }^{3}$ Código Civil francés.
} 
piamente tales, reiterando que hay acuerdo en que ello es consecuencia de que no se pueda exigir su cumplimiento forzado pero, y sin perjuicio de sus palabras, es imperioso dejar claro como punto de cierre de este apartado, que la preminencia del enfoque ético de una norma no incide en que pueda ser susceptible o no de secuelas propias del ordenamiento jurídico producto de su posible o eventual infracción.

\section{La aplicación del derecho de daños ante el incumplimiento del deber de fidelidad y de otros deberes conyugales}

Habiendo manifestado desde el comienzo que el matrimonio es una institución y no un contrato como lo expresa su definición el Código Civil (2000, art. 102) -al menos no durante su vigencia, pero sí en su nacimiento como concurso libre de voluntades ${ }^{4}$, sería contradictorio plantear una postura a partir de lo que algunos autores denominan como responsabilidad contractual (lo que en estricto rigor son los efectos de las obligaciones), sobre todo sabiendo que los deberes matrimoniales, al no constituir obligaciones, no pueden ser susceptibles de ejecución forzada y, por consiguiente, no procedería por esta vía una eventual indemnización de perjuicios al ser derecho secundario. De este modo, de ser pertinente la aplicación del estatuto de la responsabilidad, y como lo expresa Barros Bourie (2007), ésta "debe ser construida con criterios típicos de la responsabilidad extracontractual" (p. 1070). Lo recoge de esta manera también Lepin Molina (2017) quien, en un repaso al derecho comparado sobre la materia en particular, da a conocer que "así lo ha entendido la doctrina y la jurisprudencia argentina, que consideran que los daños derivados de las relaciones de familia quedan emplazados dentro de la órbita extracontractual de la responsabilidad civil" (p. 504).

De esta forma, ya reconocido el estatuto aplicable en caso de que sean procedentes los instrumentos resarcitorios que entrega el derecho de daños, ahora es necesario hacer un repaso crítico sobre las distintas líneas sostenidas sobre lo que se plantea en particular.

\footnotetext{
${ }^{4}$ Sin esta discusión competer al tema tratado, al menos resulta necesario esbozar una síntesis de las razones que sustentan lo dicho. Así, la gran mayoría de las normas que rigen los efectos del matrimonio (sean personales o patrimoniales) son de orden público, imperativas e inmodificables por la mera voluntad de los contrayentes, a diferencia de aquellas establecidas para los contratos en donde la autonomía de la voluntad de las partes es lo que prima. Aunque, a pesar de lo señalado, y adoptando lo que se dirá para efectos de este artículo, también es posible compartir que el matrimonio nace como un contrato al momento de la celebración (tras haberse otorgado el consentimiento libre y espontáneo) toda vez que, entre otras cosas, los contrayentes otorgan cierta información de su grado de compromiso y poseen también algún espacio de libertad para regular sus relaciones de familia en lo que será la vigencia lo mismo, pero una vez concretado ello deviene en una institución hasta su término.
} 
Fundamentos jurídicos y de análisis económico para la aplicación de responsabilidad civil...

\subsection{Derecho de familia, deberes matrimoniales y responsabilidad civil}

Opiniones divergentes han visto la luz en torno a la idea de la pertinencia de la aplicación de la responsabilidad civil ante el incumplimiento de las prerrogativas de carácter personales que nacen del matrimonio, pues al no haber texto expreso que contemple o rechace su concesión ha llevado tanto a los autores locales como a la jurisprudencia a abanderarse por una u otra postura. Bajo dicha mirada, para Turner Saelzer (2017), "este silencio del legislador ha sido interpretado por una parte de la doctrina nacional como la confirmación de la aplicación del régimen general de responsabilidad civil a la materia y por otra, como la expresión de su exclusión" (p. 360).

Una primera posición es la que rechaza la indemnización por infracción a los deberes maritales, la cual abraza su argumentación principalmente en dos ideas, siendo la primera que radica en el fuerte contenido ético de estos deberes y, la segunda, en la especialidad del derecho familiar. En relación con el primer presupuesto, las dudas en torno a él ya fueron despejadas en el apartado inicial de este trabajo, quedando hacerse cargo solo del segundo planteamiento, adelantando que dicha perspectiva no ha sido recogida únicamente por la literatura nacional --así, por ejemplo, Hernández Paulsen (2016, p. 111)- sino también en diversas ocasiones por los tribunales del país. Véase las sentencias: Corte de Apelaciones de Rancagua, L. H. F. M. con M. I. V. C. (2007); Corte de Apelaciones de Santiago, Rol N 7738-2007 (2009); y, Corte Suprema, R. A. P. C. con B. A. O. y F. R. M. (2012). Interesante es la postura disidente a los fallos anteriores expresada en lo resuelto por el Tribunal Constitucional en sentencia Requerimiento de inaplicabilidad por inconstitucionalidad de Lorena Riquelme Moreira (2009), al concluir que puede proceder responsabilidad civil en caso de incumplimiento grave y reiterado de deberes matrimoniales al ser ello un hecho constitutivo de ilícito civil, empero, si bien es digno de reconocimiento, el razonamiento yerra en dos aspectos: i) restringe la aplicación eventual de responsabilidad aquiliana solo en caso de infracción de deberes conyugales, cuando ella es susceptible de verificarse en otros casos como de nulidad matrimonial; $y$, ii) manifiesta que de proceder la correspondiente indemnización de perjuicios ella estaría sometida bajo el estatuto de la responsabilidad contractual, lo que como plantee en un comienzo, es una premisa errónea.

Esta postura, sin embargo, no es del todo convincente. Más aún, el argumento es insuficiente toda vez que, según Llulle Navarrete (2013) "el derecho de familia concurre en variadas ocasiones al Derecho de la Responsabilidad Civil, y más precisamente en su versión aquiliana, lo que desmiente este supuesto hermetismo" ( $p$. 289), hermetismo que también se ha mostrado reacio a aceptar de Verda y Beamonte (2007, p. 106). 
Estas interpretaciones que rechazan la aplicación de la responsabilidad civil en el ámbito de familia y en particular ante casos de infracción a los deberes que nacen del vínculo conyugal no son felices ni coherentes con el ordenamiento jurídico. En el Código Civil (2000) se manifiesta que "Por regla general, todo daño que pueda imputarse a malicia o negligencia de otra persona, debe ser reparado por ésta" (art. 2329), inclusive, muchas veces las normas contenidas en aras de la regulación de las relaciones de familia se remiten a las reglas supletorias en materia de responsabilidad que se encuentran en diversas disposiciones del Código Civil (2000) (como son los casos de acciones de filiación deducidas de mala fe, por nombrar una). Bajo este supuesto, y en palabras de Corral Talciani (2013), "no hay ninguna razón para no aplicar las reglas de la responsabilidad civil en el ámbito de familia, pues ello rompería la unidad del sistema civil y establecería una inmunidad que la ley no ha querido" ( $p$. 343). Hay que recordar que el derecho de familia por muchas características especiales que tenga sigue estando inmerso dentro del derecho civil, y ese es el fundamento de aquellos que sostienen la segunda posición sobre este ítem, quienes se abren a la aceptación de aplicar la responsabilidad civil, en el caso de incumplimiento de los deberes que nacen del vínculo matrimonial.

Dicho esto, necesario es hacer un repaso por los elementos (o requisitos) que deben estar presentes en todo caso que amerite una probable aplicación de responsabilidad civil.

\subsubsection{La capacidad}

Respecto a la capacidad, como es común en el ordenamiento jurídico, la regla general es que todas las personas sean capaces. Por ende, serán incapaces aquellos que la ley declara tales. Para estos efectos serían absolutamente incapaces: los dementes y los infantes. Respecto a esto no hay nada que agregar, más que uno de los requisitos de existencia del matrimonio es el consentimiento, por lo cual el demente, al no ser capaz de expresar una voluntad libre, no podría participar en la creación de esta institución (o celebración del contrato, recordando nuestros peros a dicho concepto); por otro lado, en materia de responsabilidad extracontractual, los mayores de dieciséis años gozan de capacidad para responder de su delito o cuasidelito civil aplicando la regla del inc. $2^{\circ}$ del art. 2319 del Código Civil (2000) y, en conjunto a los requisitos para contraer matrimonio, no existiría mayor complejidad toda vez que los mayores de dieciséis sí pueden casarse a los ojos del derecho local (con ciertos requisitos).

Esto es de suma importancia en el entendido que, desde una perspectiva económica, los sujetos racionales actúan de acuerdo con una escala de valores que le permita conseguir sus fines, y al ordenamiento jurídico velar porque las personas que voluntariamente deseen contraer matrimonio actúen racionalmente (o, en negativo, 
Fundamentos jurídicos y de análisis económico para la aplicación de responsabilidad civil...

establecer impedimentos de 'irracionalidad'), hace más sencillo el análisis económico en torno a aquél al que haré referencia en el acápite final.

Por lo expuesto, ha de estimarse que a menos que exista una incapacidad sobreviniente como la demencia después de la celebración de las nupcias (que tampoco sería relevante, toda vez que como se verá, el acto de infidelidad requiere de por sí una conducta dolosa por parte del sujeto que lo ejecuta), los contrayentes tienen total capacidad delictual a la luz del punto en discusión, toda vez que tanto el demente como el infante no pueden contraer matrimonio y, por ende, no podrían quebrantar mucho menos un deber que surja de este vínculo jurídico.

\subsubsection{El hecho imputable}

El hecho debe constituir un ilícito civil, sea un delito o cuasidelito. Así lo expresa el Código Civil (2000) al referirse al nacimiento de las obligaciones "... ya a consecuencia de un hecho que ha inferido injuria o daño a otra persona, como en los delitos y cuasidelitos..." (art. 1437). Será un delito civil en el caso que "...el hecho sea ilícito y cometido con la intención de dañar..." (Código Civil, 2000, art. 2284, inc. 3º) o cuasidelito "Si el hecho es culpable, pero cometido sin la intención de dañar..." a otro (Código Civil, 2000, art. 2284, inc. 4º).

Ahora bien, surge la duda de cómo determinar cuándo un hecho es ilícito o no lo es. Para estos efectos hay que considerar que tanto la transgresión o infracción a un deber expresamente señalado por la ley tanto como el incumplimiento al deber general sustentado en el principio alterum non laedere son determinantes a la hora de establecer si un hecho o no constituye antijuridicidad $y$, por lo tanto, ilicitud. No es necesario que la ley traiga consigo una sanción especial señalada para cada deber jurídico establecido por el legislador, toda vez que el derecho común en materia de responsabilidad es la extracontractual $y$, por ende, aplicable a todos los casos que a contrario sensu no se rijan por las reglas de los contratos. Incluso, reformulando la afirmación anterior, sería mejor constatar que con independencia de que la ley prevea efectos específicos a la infracción de un deber, ello no resulta excluyente de las reglas de la responsabilidad extracontractual pues el Código Civil (2000, art. 2329) no distingue a propósito de este ítem al utilizar la expresión "todo daño" (cuestión ya referida).

Dicho lo anterior, es pertinente traer a colación la pregunta de si es o no el incumplimiento al deber de fidelidad que nace del matrimonio un hecho ilícito. Independiente de las conclusiones apresuradas que se puedan tomar de lo expuesto en el párrafo anterior, esta hipótesis requiere un análisis más criterioso al respecto. No es posible dejar de lado disposiciones expresas que hace el legislador del deber de fidelidad, como se daba a conocer en los primeros párrafos. En su razón, el Código Civil (2000, art. 131) se ocupa de éste y no de forma antojadiza, sino que como el primer deber que surge del matrimonio; a su efecto, y en seguida, el art. 132 (Código 
Civil, 2000) ya no se refiere a él como deber, sino que a su infracción en cuanto tal a propósito del adulterio. ¿Podría serse infiel de manera culposa, es decir, producto de negligencia? No hay duda de que el infringir el imperativo de los cónyuges de guardarse fe se hace conociendo y queriendo y, por lo tanto, de forma dolosa. A esto se suma Corral Talciani (2013) al afirmar que "no parece correcto señalar que el adulterio no puede ser conceptualizado como hecho imputable; lógicamente la infidelidad, si es tal, es plenamente consciente y, por tanto, realizada con dolo" (p. 346). Con todo, hay que aclarar que no es posible subsumir la infidelidad en el concepto de dolo tal cual lo plantea el Código Civil (2000) “...intención positiva de inferir injuria en la persona o propiedad de otro" (art. 44). Nadie (hablando a nivel genérico, entendiendo que existen excepciones a la regla), en efecto le es infiel a otro con el propósito directo de dañarlo o inferir injuria en su persona, pero sí es consciente de las consecuencias que puede producir en ese otro el acto de infidelidad y las acepta, motivo por el cual podría extenderse esta caracterización de dolo a una especie de lo que sería considerado como dolo eventual, para una lectura más acabada sobre esta idea de dolo eventual, véase Opazo González (2018, pp. 173-192).

El adulterio, en sí, constituye una infracción al deber de fidelidad y es, por lo tanto, constitutivo de ilícito civil. Si un hecho es doloso o culposo, es porque es ilícito $y$, con ello, se zanja el punto en debate.

\subsubsection{El daño}

Donde hay daño puede existir responsabilidad. Diez Schwerter (2016), citando a Alessandri Rodríguez, se refiere a aquél como "todo detrimento, perjuicio, menoscabo o molestia que sufre un individuo en su persona, bienes, libertad, honor, crédito, afectos, creencias, etc." (p. 19), siendo así que la noción de daño no solo se reduce al ámbito patrimonial, sino que a la lesión de un simple interés, pudiéndose inmiscuir perfectamente a aquellos provocados en las relaciones de familia y en específico al no cumplimiento de los deberes que impone el matrimonio. Esta es la tesis aceptada mayoritariamente por la jurisprudencia nacional (Diez Schwerter, 2016, p. 21). Por lo mismo, llama la atención como ha sido constantemente rechazada la indemnización de perjuicios en los tribunales bajo este ámbito, creándose un ambiente de inmunidad para que los cónyuges puedan dañarse recíprocamente, lo que ha sido reconocido inclusive por la Corte de Apelaciones de Talca (Rol No 133-2012).

Para el caso chileno, de existir responsabilidad civil por infracción de deberes entre los cónyuges, ésta debiese regirse por el estatuto del daño moral -para una mejor comprensión del daño moral en las relaciones familiares, véase: de Verda y Beamonte (2018)- bajo el presupuesto mayormente aceptado como lo es el del equivalente al pretium doloris (precio del dolor), el que tiene su fundamento en el dolor o molestia que el hecho ilícito ocasiona en los sentimientos o afectos de una persona (Diez Schwerter, 2016, p. 82) -lo que para gran parte de la doctrina es su 
Fundamentos jurídicos y de análisis económico para la aplicación de responsabilidad civil...

concreción propiamente tal-. En ese sentido, "el daño moral existe cuando se ocasiona a alguien un mal, perjuicio o aflicción en lo relativo a sus facultades espirituales; un dolor o aflicción en sus sentimientos" (Diez Schwerter, 2016, p. 82), lo que da vasta claridad en que ello cabría en el hecho de uno de los cónyuges de no cumplir con el mandato de fidelidad, convivencia, socorro, entre otros contemplados por el Código Civil (2000). Domínguez Hidalgo (2000, p. 83), por su parte, adhiere a este planteamiento señalando que el daño moral es posible de ser concebido en el sentido más amplio posible, incluyendo todos los daños a la persona en sí misma.

El derecho comparado así lo ha recogido -aunque la honestidad intelectual llama a señalar que esto no ocurre en todos los casos, siendo a propósito de la legislación comparada la situación más notoria aquella que se introduce con la reforma al derecho de las obligaciones en el Bürgerliches Gesetzbuch ${ }^{5}$ (BGB, 1896, §253) que se refiere a los daños inmateriales, establece de forma expresa que la indemnización pecuniaria de daños que no sean materiales únicamente podrá ser exigible en los casos previstos por la ley. Sobre la Schmerzengsgeld (pérdida no pecuniaria) bajo esta mirada, ha afirmado la doctrina alemana que solo podrá ser indemnizable en los casos que se reclame indemnización por otro concepto, referido al daño material. En este orden de cosas, por lo tanto, no cabría posibilidad de demandar el resarcimiento de un daño moral por incumplimiento de deberes matrimoniales en Alemania, pues la eventual pretensión, además, deberá recaer en conjunto a un caso de lesión corporal, a la salud, a la libertad o autodeterminación sexual-, siendo el caso de la legislación francesa la cual "también ha optado por aplicar directamente las normas de responsabilidad civil, frente a la ausencia de normas particulares que reglamenten la situación de los daños causados entre cónyuges por incumplimiento de los deberes conyugales" (Vargas Aravena, 2009, p. 227), pudiendo caer dentro de la categoría de lo que en dicho ordenamiento jurídico se conoce como le préjudice d'agrément. Por otro lado, es interesante traer a colación el caso del sistema del Common Law donde también se reconoce la indemnización por daños infringidos con motivo de la relación entre cónyuges bajo la figura del loss of consortium en virtud de la que se concede el derecho a reparación por la circunstancia de la pérdida de la vida en común que se tenía entre cónyuges y similares con relación al ámbito familiar (Diez Schwerter, 2016 , p. 115). Sobre este último aspecto, es dable adelantar que cuando una persona decide contraer matrimonio con otra lo hace en el entendido de que ella le propiciará un mayor nivel de utilidad, siendo la pérdida de aquella (o de la legítima expectativa) que cabría bajo la última figura referida.

En definitiva, hay razones suficientes para aceptar la procedencia de indemnización de perjuicios por responsabilidad civil ante el incumplimiento de las prerrogativas que ven su luz con la celebración de nupcias, ¿pero es esto un absoluto? O, en otros términos, ¿toda infracción de deberes puede ser sujeta a responsabilidad civil?

\footnotetext{
${ }^{5}$ Código Civil alemán, publicado en 1896, pero que entró en vigor en 1900.
} 
Se comparte la opinión de los profesores Barcia Lehmann y Rivera Restrepo (2015), quienes sostienen que "la responsabilidad por incumplimiento de deberes del matrimonio solo procede como una causal calificada de ilicitud, o agravada de imputabilidad" (p. 42). En este mismo parámetro, Corral Talciani (2013), siguiendo a Rodríguez Guitián, plantea que "la aplicación de las reglas de responsabilidad no debe hacerse de manera indiscriminada o automática sino con la necesaria prudencia derivada de la relación familiar" (p. 384), aludiendo a que ella (la responsabilidad) no cabría ante cualquier caso de infracción de un deber marital, sino de manera única cuando esta sea de carácter grave, consciente y que efectivamente provoque un daño intolerable, sin obviar claro está los demás requisitos propios de todo daño extracontractual (Barcia Lehmann, 2007, p. 255). Ha de imaginarse, a modo de ejemplo un matrimonio entre swingers ${ }^{6}$, casi en el que difícilmente la infidelidad o el adulterio constituiría un daño intolerable en cuanto a su magnitud para uno de los cónyuges al haberse consensuado o al menos permitido de forma expresa o tácita esa forma de vida.

\subsubsection{El nexo causal}

El hecho ilícito debe ser la causa directa del daño provocado. He ahí que se hable por algunos autores de la exigencia de una imputación causal o relación de causalidad entre uno y otro, lo que en términos simples se explica a partir de una consecuencia causa-efecto.

Esta relación de causalidad, según explica Barros Bourie (2007, p. 374), se compone de dos elementos: Uno natural y otro de carácter normativo. Llulle Navarrete (2013), afirma que "...el primero consiste en que el hecho del demandado sea condición necesaria del daño, mientras que el segundo, consiste en que haya una conexión de ilicitud entre la regla de conducta y el daño que esta regla persigue" (p. 319).

Tomando en consideración lo recién mencionado, y conectándolo a lo que se hizo referencia cuando se aludió al daño como elemento de la responsabilidad civil, el llamado ahora es a determinar cuál sería el nexo de causalidad entre el hecho imputable (la infracción grave, como se dijo, de un deber conyugal) y el daño intolerable que aquél provoque. Lo más sensato (en virtud de los principios de seguridad jurídica y de economía procesal) es concluir que el vínculo causa-efecto entre ambos ha de encontrarse en la sentencia firme de divorcio por culpa fundada en la causal genérica de la Ley $N^{\circ} 19.947$ (2004, art. 54) y, además, según el № 2 del mismo art., esto es la transgresión grave y reiterada de los deberes de convivencia, socorro y fidelidad propios del matrimonio. Lo expuesto por la sencilla razón de que no cualquier incumplimiento a un deber del matrimonio puede ser causa para demandar indemnización de perjuicios por la vía extracontractual, sumado a que al momento

\footnotetext{
${ }^{6}$ Denominación para personas cuya actividad sexual va más allá de la monogamia.
} 
Fundamentos jurídicos y de análisis económico para la aplicación de responsabilidad civil...

de dictarse la sentencia de divorcio por culpa bajo las causales referidas es certeza de que la parte a quien correspondía el onus probandi logró acreditar las circunstancias que daban lugar al divorcio culposo, con la advertencia de que será así "siempre que no haya sobrevenido previa separación de hecho" (Llulle Navarrete, 2013, p. 331), pues en esa situación sería inocua.

\subsection{Compensación económica y concurrencia de responsabilidad civil}

Es menester hacer una breve mención a la compensación económica, toda vez que, de no hacerlo, posiblemente cabría en el lector la pregunta que de si admitir la procedencia de indemnización de perjuicios por incumplimiento de deberes matrimoniales no se correría el riesgo de caer en la figura non bis in ídem al existir la institución de la compensación económica como derecho post-marital que asiste a uno de los cónyuges.

Para responder a esta pregunta es necesario abordar la naturaleza de la compensación económica, más que cualquier otro asunto ${ }^{7}$. Esto toda vez que es allí donde se podrá dar fe que, ambas instituciones jurídicas (la compensación como la reparación de daños) responden a órbitas completamente distintas $y$, como tales, se mueven por su cuenta independiente de los fundamentos y objetivos de la otra.

\subsubsection{Definición y naturaleza de la compensación económica}

El legislador no entrega una definición de compensación económica, así como tampoco señala de forma textual cuál es su naturaleza. De este suerte, tanto la primera como la segunda tarea ha correspondido ser llevada a cabo por la jurisprudencia y doctrina nacional, pero no apoyados en un vacío legislativo, sino que con miras en lo establecido en la Ley $\mathrm{N}^{\circ} 19.947$ (2004, arts. 61 y 62), siendo uno el cual indica los requisitos de procedencia, mientras que el otro manifiesta cuales son los elementos a considerar para determinar el quantum de la misma (tales como la duración del matrimonio o acuerdo de unión civil, la situación patrimonial, la existencia de buena o mala fe, la edad y estado de salud, entre otras).

En síntesis, los requisitos para la procedencia de la compensación económica son: i) Existencia de un matrimonio o Acuerdo de Unión Civil; ii) Declaración de nulidad del matrimonio o divorcio, o término del acuerdo de unión civil vigente; iii) Ausencia o reducción de actividad remunerada del cónyuge o conviviente civil que no pudo ejercer una actividad de ese tipo, o pudo hacerlo, pero en menor medida de lo que podía y/o quería; iv) Dedicación al cuidado del hogar común y/o de los hijos; y, v) Existencia de un menoscabo económico sufrido por el cónyuge o conviviente civil.

\footnotetext{
${ }^{7}$ Por lo mismo se advierte que en estas líneas se encontrará de forma exclusiva un somero análisis en torno a la naturaleza de la compensación económica, más no cuestiones relativas a la forma de pago, determinación del monto o aspectos procesales que son propios de ella y nada tienen de relevante para este artículo.
} 
Estos requisitos, que como se dijo se desprenden de la Ley $\mathrm{N}^{\circ} 19.947$ (2004, art. 61) son imprescindibles a la hora de establecer una definición de lo que es la compensación económica. Ahora bien, esto en ningún caso quiere decir que como consecuencia de ello todos los conceptos que giren en torno a la institución que se está tratando sean uniformes. Muy por el contrario, varían de acuerdo con la naturaleza y/o función que le adjudiquen los autores nacionales como los tribunales de justicia a la hora de dictar sus sentencias. Así, se ha llegado a definir como:

El derecho que le asiste al cónyuge más débil (normalmente la mujer) a que se le compense el menoscabo económico que, producido el divorcio o nulidad, experimentará por no haber podido desarrollar durante el matrimonio una actividad remunerada o lucrativa, o haberlo hecho en menor medida de lo que quería y podía por haberse dedicado al cuidado de los hijos o las propias labores del hogar. (Ramos Pazos, 2010, p. 120)

Si bien esta definición parece criticable por el tono machista que emplea pues si bien estadísticamente las mujeres son las que demandan mayormente compensación económica, la Ley N 19.947 (2004, art. 61) dice claramente que este derecho corresponde a cualquiera de los cónyuges- o por el presumible sesgo de carácter compensatorio de la institución, sirve transcribirla en estas líneas a modo de referencia para el lector.

Otros autores, yendo más allá, han llegado a afirmar que la compensación económica tendría como fundamento la pérdida de oportunidad (Lepin Molina, 2010, pp. 64-71), de los daños económicos y la indemnización por daño moral provocados en el matrimonio (Barrientos Grandon y Novales Alquézar, 2004, p. 404 y ss.) asumiendo una naturaleza de la compensación de carácter resarcitorio o como de un presupuesto de indemnización de perjuicios-, e inclusive, que tiene una función punitiva (Domínguez Hidalgo, 2005, p. 115). Estas ideas han llevado a asumir (como en los primeros dos casos) que la compensación económica tiene una naturaleza estrictamente patrimonial, fundada en, como se dijo, el carácter resarcitorio con sus bases sea en la indemnización de perjuicios, en un paliativo o en el principio de sanción al enriquecimiento sin causa que tendría aquella, noción que ha sido adoptada por la jurisprudencia mayoritaria de los tribunales superiores de justicia del país. véase sentencias de: Corte de Apelaciones de Rancagua, Rol N 529-2006 (2006); Corte de Apelaciones de Antofagasta, E. S. A. con A. M. C. M. (2006); Corte de Apelaciones de Concepción, G. A. B. E. con M. M. R. S. (2007); y, Corte Suprema, E. V. G.-H. con C. J. B., (2009).

Dado a conocer lo anterior, no se puede adherir a lo indicado por dicha doctrina y lo asumido por las cortes de apelaciones y la Corte Suprema. Ello, toda vez que, de asumir dicha postura, efectivamente se estaría en presencia del non bis in ídem, al existir una doble indemnización de perjuicios (en caso de procedencia de compensación económica y responsabilidad civil por incumplimiento de las prerro- 
Fundamentos jurídicos y de análisis económico para la aplicación de responsabilidad civil...

gativas que nacen del vínculo matrimonial), más aún cuando el legislador a todas luces no quiso darle a la institución referida una naturaleza pecuniaria. Al contrario, la naturaleza de la compensación económica es eminentemente extrapatrimonial y, por lo tanto, no se contrapondría a la potencial procedencia de indemnización de perjuicios por infracción a un deber marital, como se pasará a explicar en el punto que tocaré a continuación.

\subsubsection{El pago de un monto por concepto de compensación económica no es in- compatible con la indemnización de perjuicios por incumplimiento de deberes que derivan del matrimonio}

La compensación económica, se dijo, tiene una naturaleza extrapatrimonial, lo cual es muy loable toda vez que, en palabras de Barcia Lehmann (2008) intentar importar criterios netamente patrimoniales a ella resulta muy cuestionable. El hecho que se pague generalmente en dinero (pues también puede constituirse un derecho real a favor del cónyuge que demanda) no significa que la institución tenga una naturaleza de carácter patrimonial. Los alimentos, a modo de ejemplo ${ }^{8}$, a pesar de que son pagados en una suma de dinero, tienen indiscutiblemente un carácter extrapatrimonial en virtud de obedecer al deber de socorro que impone el matrimonio, respecto a los cónyuges, y otros referidos a los demás miembros de la familia a quienes se les debe. En efecto, los alimentos se encuentran fundados bajo los principios de derecho a la vida, derecho a un nivel de vida adecuado, principio del interés superior del niño, igualdad ante la ley y protección al cónyuge más débil (último que comparte con la institución de la compensación económica). Para más información sobre los alimentos, un reciente e interesante tratamiento de dicha área se encuentra en Greeven Bobadilla y Orrego Acuña (2018).

La compensación económica, así, obedece a criterios propios que informan el derecho de familia que se mantienen al margen de los presupuestos que se exigen en el derecho patrimonial (como sostenían los autores ya mencionados), siendo su sustento principal el principio de protección al cónyuge más débil y al de protección a la familia. A este propósito, los profesores Barcia Lehmann y Riveros Ferrada (2011) de forma muy erudita explican que:

La funcionalidad de la compensación económica está dada por la distribución del trabajo, en el seno de la familia, con miras a la protección del hogar común y sobre todo de los hijos comunes. [...] Busca lograr (la ins-

\footnotetext{
${ }^{8}$ Se niega que la compensación económica tenga el carácter de alimentos por los siguientes motivos: i) La prestación procede entre cónyuges o convivientes civiles, por lo que se extinguiría una vez disuelto el matrimonio o terminado el acuerdo de unión civil; ii) No es requisito el estado de necesidad en la compensación económica; iii) La sentencia que se refiere a la compensación económica produce cosa juzgada material y formal, mientras que respecto a los alimentos es meramente formal; $y$ iv) De acuerdo a la Ley № 19.947 (2004), si la compensación se paga en cuotas, ellas se considerarán alimentos solo para el efecto de su cumplimiento (apremios y otras medidas adicionales que, como se dejó en claro al principio del acápite, no son objeto de este estudio).
} 
titución referida) acuerdos eficientes, que permitan que un cónyuge pueda renunciar a la vida laboral o profesional de forma temporal o definitiva para dedicarse al cuidado de los hijos o al hogar común. (p. 262)

Teniendo como sustento todos los argumentos entregados, no queda más respecto a este punto asumir que la procedencia de indemnización de perjuicios por incumplimiento de deberes conyugales y de compensación económica no sería incompatible, pues mientras la primera se funda en un carácter patrimonial, la segunda tiene un fundamento y contenido estrictamente extrapatrimonial.

\subsubsection{Acuerdo de Unión Civil e incumplimiento ¿de deberes?}

Se define el Acuerdo de Unión Civil como "...un contrato celebrado entre dos personas que comparten un hogar, con el propósito de regular los efectos jurídicos derivados de su vida afectiva en común, de carácter estable y permanente" (Ley $\mathrm{N}^{\circ}$ $20.830,2015$, art. 1). Definición que resultó una innovación local y motivo de celebración por parte de la comunidad, toda vez que, a diferencia de la institución matrimonial, este contrato no requiere de la heterosexualidad como requisito de existencia de este, pudiéndose celebrar por parejas heterosexuales u homosexuales. De esta manera, personas que hasta el día de su entrada en vigor vivían en concubinato o en convivencia (desprotegidas de una forma abrumadora por el derecho), podían optar a resguardar sus relaciones patrimoniales y de vida en común, en general.

Se dice en general porque, a pesar de su indiscutible aporte destacado en los párrafos anteriores, la ley adolece de dos vicios que el día de hoy dejarlos pasar por alto significaría un acto miope por parte los ciudadanos abocados al mundo jurídico y político. Son, en efecto, deficiencias de carácter jurídicas y políticas que pueden verse traducidas en dos planteamientos: El primero, es que el Acuerdo de Unión Civil (Ley $N^{\circ} 20.830,2015$ ) comete el error de reducir (o pretender hacerlo) las relaciones de familia al exclusivo arbitrio de las partes; $y$, el segundo, que la ley como tal está establecida perpetúa la discriminación del ordenamiento jurídico y en específico del derecho de familia a las relaciones de parejas entre el mismo sexo.

En lo que al primer punto respecta, al leer las disposiciones de la Ley $N^{\circ} 20.830$ (2015) pareciese que ésta se aboca casi con exclusividad a regular temas de naturaleza patrimonial. En ese sentido se extraña que el legislador no haya tomado en cuenta en su articulado deberes que sí comprende el matrimonio, refiriéndose el Acuerdo de Unión Civil solamente a la ayuda mutua, dejando de lado otros tales como el guardarse fe (o fidelidad), el respeto y la protección, entre otros. De este modo, y en relación con ello, no deja de sorprender cómo el acuerdo parece prescindir de finalidades propias, permitiendo afirmar de lleno que es un contrato el cual carece de fines. Así, el cuerpo normativo omite referirse a cuestiones que, al igual que las mencionadas, resultan de suma importancia para una concepción integral de la familia, ya sea con relación a los alimentos recíprocos (derecho a alimentos que se ha entendido 
Fundamentos jurídicos y de análisis económico para la aplicación de responsabilidad civil...

incorporado en virtud del principio de igualdad) entre convivientes civiles o la nula referencia a los hijos, por mencionar algunas pocas.

¿Cuánto se aleja la celebración de un Acuerdo de Unión Civil a una compraventa o un mandato? Permitiendo la hipérbole, pareciese no distar mucho, toda vez que no existen normas que den luces de imponer el interés de la familia (orden público) por sobre el simple consensualismo de un contrato (orden privado). Sorprenderá a muchos saber que la ley es permisiva al establecer que uno solo de los convivientes puede poner fin al acuerdo (mediante escritura pública o acta otorgada ante oficial del Registro Civil) sin necesidad de notificar al otro de ello, pues si bien exige el cuerpo normativo que se le notifique a aquél, el mismo también deja de manifiesto que la falta de dicha diligencia no afectará la terminación del Acuerdo de Unión Civil. Haciendo uso de una expresión jocosa: tal cual 'pololeo' por escrito. Hay evidente claridad entonces que la Ley $\mathrm{N}^{\circ} 20.830$ (2015) es bastante distante de lo que es un matrimonio y, por consecuencia, es concreción de la discriminación que la legislación hace de las parejas del mismo sexo ya que, al ellas no poder acceder al matrimonio a diferencia de las heterosexuales, tienen como única alternativa la celebración de un Acuerdo de Unión Civil, el cual si bien tiene el gran punto a favor de equiparar lo respectivo a derechos sucesorios entre los cónyuges a los convivientes civiles, carece de una gran variedad de otros aspectos vistos con anterioridad, sin los cuales resulta difícil consolidar las pretensiones de afianzar efectivas relaciones de familia entre los individuos.

Por todo lo dicho, cabe concluir que imposible resultaría aplicar el estatuto de responsabilidad por incumplimiento de deberes al término del Acuerdo de Unión Civil pues éste no impone ninguno para los convivientes civiles.

\section{Análisis económico del derecho de daños producidos en el matri- monio}

Puede decirse con toda seguridad que el Análisis Económico del Derecho, tal como se conoce hoy, es algo relativamente nuevo. Hasta antes de los años 70', el derecho y economía era sinónimo del análisis económico del derecho antimonopólico (o antitrust) y con toda razón, pues el mundo jurídico confiaba a la economía solamente la explotación de leyes antimonopólicas, sin perjuicio de que existían ya por ese entonces textos más innovadores.

Expresiones como law and economics, economics and the law, legal and economic analysis y economic interpretation of law eran comunes para referirse al 'antiguo' análisis económico del derecho, siendo en la literatura especializada que se introdujeron nuevas expresiones como new law and economics y economic analysis of law para diferenciar a la corriente de pensamiento surgida en los 60' de aquellos otros términos circunscritos que fueron utilizados con sentidos diferentes a los actua- 
les. Este movimiento del nuevo derecho y economía (que no es una mera herramienta analítica como sostienen algunos) ve su auge en los Estados Unidos con los artículos publicados por Calabresi (1961) sobre los cuasidelitos y Coase (1960) referido al costo social y se ha masificado logrando penetrar con trabajos académicos en Europa e Hispanoamérica, los cuales ponen de manifiesto cómo la disciplina pasa a ocuparse de temas variados del derecho común, como lo son el derecho de propiedad, de los cuasidelitos, de los contratos e, inclusive, el derecho de familia (Becker, 1991).

El Análisis Económico del Derecho puede definirse como "una corriente de pensamiento jurídico que busca analizar fenómenos legales y formular nuevos paradigmas en el derecho bajo el uso de la clave económica como la principal vía para alcanzar la eficiencia" (Castro Azócar , 2019, p. 30). Así, en palabras de Posner (2007):

No deben confundirse la teoría económica del derecho y la teoría de la eficiencia del derecho común. La primera trata de explicar el mayor número posible de fenómenos legales mediante el uso de la economía. La segunda (que está incluida en la primera) postula una meta económica específica para un subconjunto limitado de reglas e instituciones legales. (pp. 57-58)

De este modo, el Análisis Económico del Derecho está constituido por un enfoque positivo y normativo del derecho que interactúa en conjunto por medio de las lógicas económicas de la maximización de los beneficios que los individuos racionales persiguen. La economía "ofrece una teoría del comportamiento para pronosticar cómo responderán los individuos ante las leyes" (Cooter y Ulen, 2016, p. 16).

Esta lectura de carácter costo-beneficio en miras de la eficiencia, entenderá cualquier sabido en nociones fundamentales de economía, no limita sus fronteras en una idea de beneficio traducida en una avaluación en dinero, sino que más bien se extrapola a las distintas aristas de la vida. O, como lo explica la profesora Querol Aragón (2014), éste "se realiza dentro de un determinado contexto de preferencias, lo cual se traduce a su vez en un nivel de bienestar de los agentes" (p. 16), nivel de bienestar que se mide a través de la utilidad obtenida como concepto abstracto, "pues también incluye conceptos no cuantificables como es el altruismo [...] o de obtener bienes diferentes a los materiales o de consumo, como pueden ser el amor, la alegría o la desilusión" (Querol Aragón, 2014, p. 16). En aquel entendido, y como lo manifiesta un autor: "... cada uno de nosotros, individualmente, escoge, algunas veces, padecer algún dolor o sacrificio para obtener un beneficio mayor o para evitar un daño más grande [...] En cada caso, algún costo es impuesto en razón de un bien mayor superior" (Nozick, 2012, p. 44).

Bien mayor superior que, como se afirmó, puede ser sinónimo de una utilidad pecuniaria, como de una mera liberalidad o simplemente un estado de satisfacción 
Fundamentos jurídicos y de análisis económico para la aplicación de responsabilidad civil...

personal como es el caso de la vida en familia o en pareja, cuestión que se aborda aquí.

La eficiencia es el fin del derecho y economía -en lo que compete a qué se entiende por 'eficiencia', ha de adherirse a la opinión expresada por Barcia Lehmann (1998), quien sostiene que "la teoría del máximo beneficio social (Social Welfare) Ilena de contenido normativo de una mejor forma el principio de la eficiencia" (p. 152)- y ésta incumbe a todo ámbito de la vida social, sea político, jurídico o familiar. Es entonces, bajo esta premisa, que se analizará si desde esta corriente de pensamiento la aplicación de responsabilidad civil ante el incumplimiento de deberes matrimoniales como mecanismo para lograr la eficiencia en las relaciones maritales.

\subsection{Aplicación del Análisis Económico del Derecho a los daños produci- dos por incumplimiento de deberes matrimoniales}

Se pudo advertir en el enunciado de este capítulo que el Análisis Económico del Derecho generalmente ha recaído sobre materias que incumben derechamente relaciones de corte patrimonial. Empero, existen obras clásicas como las de Becker (1980 y 1991) y Posner (2007) que demuestran que esta corriente de pensamiento (o movimiento, como se le quiera llamar) es extrapolable a cualquier arista de lo jurídico, inclusive aquellas que tienen 'un componente más moral' como comúnmente se hace referencia a la hora de tratar el derecho de familia, lo que en definitiva "permite entender cómo evitar el desperdicio de otros recursos no necesariamente materiales y tangibles" (Bullard González, 2012, p. 59) como lo pueden ser, por ejemplo, los afectos en una relación marital.

En el particular, el establecimiento del divorcio vincular, y en específico del divorcio culposo en Chile con la Ley $N^{\circ} 19.947$ (2004), si bien trajo soluciones a personas que deseaban poner fin a su vínculo matrimonial o se veían imperativamente en la necesidad de ello, hasta hoy contiene algunas problemáticas que si bien para algunos pueden significar meros casos aislados, pueden dar lugar a dificultades convergentes con contradicciones a la misma institución matrimonial. En esta línea, Posner (2007) afirma lo siguiente:

En un sistema que permite el divorcio con causa, un esposo que desea 'salirse' del matrimonio tendrá el incentivo para tratar tan mal a su esposa que ella se verá obligada a demandar el divorcio, siempre que el pago de alimentos $\mathrm{u}$ otros remedios no arrojen los costos totales del maltrato sobre los hombros del esposo, como ocurriría a menudo en un sistema en el que el litigio sea lento, costoso e incierto. (p. 246) ${ }^{9}$

\footnotetext{
${ }^{9}$ Respecto al lenguaje, hay que tener en consideración que, en Anglo américa, símil es 'esposo' a 'cónyuge', a diferencia de lo que ocurre en Chile donde son dos instituciones distintas.
} 
El divorcio por culpa (o con causa, como le llama el autor) puede generar incentivos perversos para poner fin al vínculo conyugal a través de la maquinación de uno de los cónyuges en desmedro del otro e inclusive de los propios hijos. Pero, es más, todavía esta maquinación puede ser perpetuada por ambos cónyuges que deseen poner fin de forma más expedita al vínculo matrimonial y pasar por alto el plazo que les impone la Ley $N^{\circ} 19.947$ (2004, art. 55) respecto al cese de la convivencia de tres años por 'divorcio unilateral o remedio' y de un año en caso del llamado (malamente) 'divorcio de mutuo acuerdo'.

Piénsese, a modo de ejemplo, cónyuges que desean la terminación de su matrimonio. Contratan a un abogado quien les recomienda fingir que uno de los cónyuges le fue infiel al otro, de manera grave y reiterada, lo cual supuestamente tornó intolerable la vida en común. Habiendo sido advertido de la eventual mancha social que eso podría costarle al falso cónyuge culpable, éste acepta toda vez que, en lenguaje del Análisis Económico del Derecho, dicho costo es menor al beneficio que le reportará el término del vínculo conyugal. De modo que, entablando toda una performance, consiguen que el tribunal dicte sentencia que declare el divorcio por culpa. Esto no quiere decir que nuestros jueces sean torpes o fáciles de engañar, sino que solamente es un hecho que podría darse debido al factor mencionado en la introducción de este trabajo, referido a la desvalorización del matrimonio.

Tomando en consideración la situación hipotética planteada por Posner (2007) más la que fue esgrimida en el párrafo anterior, hace sentido que (y si es que consideramos la estabilidad del matrimonio como un bien deseado) se procure implementar mecanismos que generen incentivos para que los cónyuges no cometan infracción a sus deberes maritales, en específico que no sean infieles. Dicho esto, asumir la procedencia de indemnización de perjuicios por incumplimiento de dichos deberes sería el mecanismo adecuado para desincentivar la conducta del sujeto culposo o, dicho de otra manera, constituirá una barrera que hará replantearse el ejecutar o no determinado acto.

Imagínese ahora que el cónyuge ve la oportunidad de serle infiel al otro (por esos placeres de la carne o por el hecho de haber encontrado una conexión emocional que no tiene con su pareja), ya no solo se verá subsumido a la consecuencia del divorcio y de la compensación económica por su quehacer, sino que, además, a una eventual condena a pagar perjuicios por ocasionar daño a otro. Así, esto es del todo eficiente desde un punto de vista económico. Cabe preguntarse ahora el cómo podría llegar a serlo (eficiente), para lo cual fructífero será acudir al óptimo de Pareto, el cual dice que una asignación de recursos será eficiente si cualquier mejora a esa asignación no podría hacerse sin empeorar a otro o, como dice Yrarrázaval Covarrubias (2012), "se produce cuando la asignación de recursos es tal que no resulta posible mejorar la situación de unos de los agentes económicos sin perjudicar la de cualquier otro" (p. 319); no obstante, "Ios conceptos paretianos de eficiencia, si se aplican 
Fundamentos jurídicos y de análisis económico para la aplicación de responsabilidad civil...

a todas las decisiones de política pública, podrían llevar a una acción gubernamental muy limitada pues, después de todo, todos tendrían que estar de acuerdo con dicha política" (Harrison, 2016, pp. 39-40), debiendo, según algunos autores, acudir a otra concepción de eficiencia que supere dichas problemáticas.

Ante la necesidad expuesta con anterioridad es como surge la llamada eficiencia de Kaldor-Hicks, en el entendido de que un acto será eficiente si los individuos que se encuentren en mejores condiciones con la política o el cambio se verán tan beneficiados como para compensar a los que están en peor situación por su aplicación (en este caso, el cónyuge inocente al sufrir un perjuicio), siendo la clave en estas situaciones no la compensación real, sino la potencial.

La aceptación de la procedencia de los instrumentos del derecho de daños ante el incumplimiento de deberes matrimoniales no solo desincentivaría la comisión de conductas que sean causa de una ruptura matrimonial, sino que también constituiría una vía reparatoria para el cónyuge inocente ante costos que pueden verse reflejados en "un tiempo perdido (inversión) al ser obvio que has elegido erróneamente a tu pareja" (Querol Aragón, 2014, p. 189) e, inclusive, también en "la dificultad (cada vez mayor) de encontrar otra persona afín que impida la soledad y te aporte todos los aspectos positivos de cariño, comprensión y compañía propios de una pareja feliz". (Querol Aragón, 2014, p. 189)

Esto último expuesto tiene sentido toda vez que, como se hizo mención en lo referido al daño, la persona que decide contraer matrimonio debido al carácter voluntario del mismo, espera obtener una utilidad de la otra, razón por la cual elige a aquella para contraer el vínculo y no a los demás pretendientes. $\mathrm{O}$, dicho de otra forma, "una persona decide casarse cuando la utilidad esperada del matrimonio excede la utilidad esperada de permanecer soltero, o la de dedicar más tiempo a la busca de la pareja" (Becker, 1980, p. 16). Por lo mismo, la pérdida de esa maximización de utilidad debe ser reparada, pero como los deberes que impone el matrimonio no son pecuniarios, esta utilidad perdida ha de ser compensada a través del supuesto de indemnización por daño moral.

En resumen, el Análisis Económico del Derecho o nuevo derecho y economía, constituye una corriente jurídica que sirve para encontrar soluciones a este tipo de problemas complejos por la subjetividad misma de las relaciones interpersonales, que no ven posibilidades de ver respuestas exclusivamente en los cojines de la moral y la ética que muchas veces otorgan mecanismos que son intrusivos en la vida privada de las personas. 


\section{Conclusiones}

Sintetizando, es posible a partir de todo lo referido con anterioridad, llegar a las siguientes conclusiones:

1. Los deberes matrimoniales son deberes jurídicos, no morales como se ha pretendido imponer. Distinto es que no constituyan obligaciones (siendo lo primero el género y lo segundo la especie), pues, al estar descritos y sancionados en la ley, de por sí ya se alejan de ser un simple deber moral.

2. A pesar del rechazo sistemático de los tribunales de justicia a aceptar la procedencia de indemnización de perjuicios por incumplimiento de deberes, abunda la doctrina nacional que muestra su rechazo a dicha postura jurisdiccional toda vez que, o si bien admiten su perfecta aplicación, llegan a consenso en que el rechazo de plano no es una buena alternativa. Asimismo, la legislación, doctrina y jurisprudencia extranjera da muestras de que este fenómeno (de responsabilidad civil por infracción a deberes que nacen del matrimonio) no es algo nuevo, sino que constituye una aplicación de los principios comunes del derecho.

3. El admitir responsabilidad civil por incumplimiento de deberes conyugales no es incompatible con la procedencia de la compensación económica, afirmación que se sustenta en la naturaleza disímil de una y otra institución jurídica.

4. No puede proceder indemnización por incumplimiento de deberes en un acuerdo de unión civil, toda vez que dicho contrato prescinde de lo que se refiere a efectos personales directos como lo son los deberes. Nadie, por lo tanto, puede alegar reparación en el incumplimiento de algo que nunca fue exigible.

5. Es posible afirmar que desde la perspectiva del análisis económico del derecho la admisión de indemnización de perjuicios por incumplimiento de deberes que nacen de la unión conyugal. Desde esta corriente de pensamiento jurídico, la aceptación de su procedencia constituiría un incentivo para que las parejas no ejecuten conductas contrarias a estos deberes con el fin de poner fin al matrimonio, como asimismo es concordante con la reparación de la pérdida de utilidad que sufre el cónyuge inocente producto la infracción y posterior divorcio en consecuencia de ese mismo hecho.

\section{Referencias Bibliográficas}

Abeliuk Manasevich, R. (2014). Las obligaciones (6a ed., Vol. 1). Santiago: Legal Publishing Chile.

Barcia Lehmann, R. (1998). Los contratos desde la perspectiva del análisis económico del derecho. lus et praxis, 4(2), 149-176. Recuperado de https://bit.ly/2PCAiFO 
Fundamentos jurídicos y de análisis económico para la aplicación de responsabilidad civil...

Barcia Lehmann, R. (2007). Lecciones de derecho civil chileno: de las fuentes de las obligaciones. Santiago: Jurídica de Chile.

Barcia Lehmann, R. (2018). La imperiosa necesidad de no confundir la compensación económica con la indemnización de perjuicios. En C. Domínguez Hidalgo (Coord.), Estudios de derecho de familia (Vol. 3, pp. 479-502). Santiago: Legal Publishing.

Barcia Lehmann, R., y Rivera Restrepo, J. M. (2015). ¿En qué casos el incumplimiento de deberes del matrimonio genera responsabilidad civil? lus et praxis, 21(2), 19-60. doi: $10.4067 / \mathrm{s} 0718-00122015000200002$

Barcia Lehmann, R., y Riveros Ferrada, C. (2011). El carácter extrapatrimonial de la compensación económica. Revista chilena de derecho, 38(2), 249-278. doi: $10.4067 /$ s0718-34372011000200004

Barrientos Grandon, J. (2011). Derecho de las personas: el derecho matrimonial. Santiago: Legal Publishing.

Barrientos Grandon, J., y Novales Alquézar, A. (2004). Nuevo derecho matrimonial chileno: Ley N¹9.947: celebración del matrimonio, separación, divorcio y nulidad. Santiago: LexisNexis.

Barros Bourie, E. (2007). Tratado de responsabilidad extracontractual. Santiago: Jurídica de Chile.

Becker, G. S. (1980). El enfoque económico del comportamiento humano. Información comercial española, (557), 11-18.

Becker, G. S. (1991). A treatise on the family. Cambridge, MA: Harvard University Press.

Bürgerliches Gesetzbuch. Reichsgesetzblatt, Berlin, Deutschen Reiches,18. August 1896. Recuperado de https://bit.ly/3f3JWLi

Bullard González, A. (2012). La economía de los contratos. En R. Cooter y H. Acciarri (Dirs.), Introducción al análisis económico del derecho (pp. 45-120). Santiago: Legal Publishing.

Calabresi, G. (1961). Some thoughts on risk distribution and the law of torts. The Yale law journal, 70(4), 499-553. doi: 10.2307/794261

Castro Azócar, F. (2019). Análisis económico del derecho regulatorio. Santiago: Hammurabi.

Coase, R. H. (1960). The problem of social cost. Journal of law and economics, 3, 1-44. Recuperado de https://bit.ly/3e4kDID 
Código Civil. Diario Oficial de la República de Chile, Santiago, Chile, 30 de mayo de 2000. Recuperado de http://bcn.cl/2f6t3

Código Civil y Comercial de La Nación. Ley N²6.994. Boletín Oficial de la República Argentina, Buenos Aires, Argentina, 01 de agosto de 2015. Recuperado de https://bit.ly/3yqvdSh

Código Civil. Ley №340. Registro Nacional 1863/69, Buenos Aires, Argentina, 25 de septiembre de 1869. Recuperado de https://bit.ly/3fzYt0g

Cooter, R. D. y Ulen, T. (2016). Derecho y economía. México: Fondo de Cultura Económica.

Corral Talciani, H. (2013). Lecciones de responsabilidad civil extracontractual (2a ed.). Santiago: Legal Publishing.

Diez Schwerter, J. L. (2016). El daño extracontractual: jurisprudencia y doctrina. Santiago: Jurídica de Chile.

Domínguez Hidalgo, C. A. (2000). El daño moral (Vol. 1). Santiago: Jurídica de Chile.

Domínguez Hidalgo, C. A. (2005). El convenio regulador y la compensación económica. Cuadernos de extensión jurídica, (11), 91-122. Recuperado de https://bit.ly/2Rc9Kvw

E. S. A. con A. M. C. M., Rol N 1016-2006 (Corte de Apelaciones de Antofagasta 6 de diciembre de 2006). Recuperado de https://westlawchile.cl id: CL/JUR/5825/2006

E. V. G.-H. con C. J. B., Rol N 904-2009 (Corte Suprema 27 de abril de 2009). Recuperado de https://westlawchile.cl id: CL/JUR/7949/2009

G. A. B. E. con M. M. R. S., Rol N 1947-2007 (Corte de Apelaciones de Concepción 3 de abril de 2008). Recuperado de https://westlawchile.clid: CL/JUR/5636/2008

González Isla, C. (2016, Septiembre 20). El 73\% de los niños nació fuera del matrimonio, la cifra más alta de la historia. La Tercera. Recuperado de https://bit.ly/33YO1Kn

Greeven Bobadilla, N., \& Orrego Acuña, J. A. (2018). Alimentos y su ejecución en materia de familia. Santiago: Der.

Güitrón Fuentevilla, J. (2016). Concepto de derecho familiar, sus elementos, el orden público y el interés social. En C. Lepin Molina y M. Gómez de la Torre (Coords.), Estudios de derecho familiar (pp. 9-49). Santiago: Legal Publishing.

Harrison, J. L. (2016). Law and economics in a nutshell (6a ed.). St. Paul, MN: West Academic. 
Fundamentos jurídicos y de análisis económico para la aplicación de responsabilidad civil...

Hernández Paulsen, G. (2016). Las consecuencias de la infracción de deberes matrimoniales no dan lugar a indemnización. Revista chilena de derecho privado, (27), 95139. doi: $10.4067 / \mathrm{s} 0718-80722016000200003$

Lepin Molina, C. (2010). La compensación económica: efecto patrimonial de la terminación del matrimonio. Santiago: Jurídica de Chile.

Lepin Molina, C. (2017). Derecho familiar chileno. Santiago: Legal Publishing.

Ley $N^{\circ}$ 19.947. Establece Nueva Ley de Matrimonio Civil. Diario Oficial de la República de Chile, Santiago, Chile, 17 de mayo de 2004. Recuperado de http://bcn.cl/2fctd

Ley N²0.830. Crea el Acuerdo de Unión Civil. Diario Oficial de la República de Chile, Santiago, Chile, 21 de abril de 2015. Recuperado de http://bcn.cl/2gbdj

L. H. F. M. con M. I. V. C., Rol N 672-2007 (Corte de Apelaciones de Rancagua 29 de octubre de 2007). Recuperado de https://westlawchile.cl id: CL/JUR/6896/2007

Llulle Navarrete, P. (2013). Divorcio, compensación económica y responsabilidad civil conyugal. Santiago: Legal Publishing.

Nozick, R. (2012). Anarquía, estado y utopía. México: Fondo de cultura económica.

Opazo González, M. (2016). Nuevamente a favor de la indemnización de perjuicios en caso de incumplimiento de los deberes matrimoniales. En C. Domínguez Hidalgo (Coord.), Estudios de derecho de familia (Vol. 3, pp. 173-192). Santiago: Legal Publishing.

del Picó Rubio, J. (2016). Derecho de familia. Chile: Legal Publishing.

Posner, R. A. (2007). El análisis económico del derecho. México: Fondo de Cultura Económica.

Querol Aragón, N. (2014). Análisis económico del derecho. Madrid: Dykinson.

Quintana Villar, M. S. (2015). Derecho de familia (2a ed.). Valparaíso: Universitaria de Valparaíso.

Ramos Pazos, R. (2010). Derecho de familia (7a ed., Vol. 1). Santiago: Jurídica de Chile.

R. A. P. C. con B. A. O. y F. R. M., Rol N² 263-2010 (Corte Suprema 13 de junio de 2012). Recuperado de https://westlawchile.cl id: CL/JUR/1094/2012

Requerimiento de inaplicabilidad por inconstitucionalidad de Lorena Riquelme Moreira Juez de Familia del Juzgado de Osorno, respecto del artículo $2^{\circ}$ transitorio de la Ley 19.947, en rit C - 1103 - 2008 y ruc No 08 - 2020 - 8921 -7 del Juzgado de Familia de Osorno, Rol No 1423-2009 (Tribunal Constitucional 31 de diciembre de 2009). Recuperado de https://bit.ly/2RB1aqq 
Rodríguez Pinto, M. S. (2017). Manual de derecho de familia. Santiago: Jurídica de Chile.

Rol No 133-2012 (Corte de Apelaciones de Talca 30 de agosto de 2012). Recuperado de Recuperado de https://westlawchile.cl id: CL/JUR/5033/2012

Rol N $529-2006$ (Corte de Apelaciones de Rancagua 20 de julio de 2006). Recuperado de https://westlawchile.cl id: CL/JUR/1889/2006

Rol N ${ }^{\circ} 7738-2007$ (Corte de Apelaciones de Santiago 10 de noviembre de 2009). Recuperado de https://westlawchile.cl id: CL/JUR/3249/2009

Ruz Lártiga, G. (2014). Explicaciones de derecho civil: derecho de las personas en familia (Vol. 5) Santiago: Legal Publishing.

T13. (2019, Abril 10). INE confirma: En 2017 hubo 12 mil nacimientos menos que en 2016. Recuperado de https://bit.ly/3u4bG6Z

Tapia Rodríguez, M. (2016). Contra la indemnización de perjuicios por incumplimiento de deberes conyugales. En C. Lepin Molina y M. Gómez de la Torre (Coords.), Estudios de derecho familiar (Vol. 1, pp. 163-180). Santiago: Legal Publishing.

Turner Saelzer, S. (2017). Responsabilidad civil entre convivientes civiles por daños asociados al AUC. En M. Acuña San Martín y J. Del Picó Rubio (Eds.), Estudios de derecho familiar (pp. 359-368). Talca: Universidad de Talca.

Vargas Aravena, D. (2009). Daños civiles en el matrimonio. España: La Ley.

de Verda y Beamonte, J. R. (2007). Responsabilidad civil y divorcio en el derecho español: resarcimiento del daño moral derivado del incumplimiento de los deberes conyugales. Actualidad jurídica, 7(15), 93-124. Recuperado de https://bit.ly/3nwzleG

de Verda y Beamonte, J. R. (2018). Persona y familia: escritos selectos. Chile: Hammurabi.

Yrarrázaval Covarrubias, A. (2012). Diccionario jurídico-económico. Santiago: Universidad Católica de Chile.

\section{Para citar este artículo bajo Norma APA 6a ed.}

Castro Azócar, F. J. (2021). Fundamentos jurídicos y de análisis económico para la aplicación de responsabilidad civil por incumplimiento de deberes matrimoniales en el derecho chileno Revista de Derecho (Coquimbo. En línea), 28, e3759. https://doi.org/10.22199/issn.0718-9753-2021-00011 